\title{
Sleep and Fibromyalgia
}

\author{
Fumiharu Togo ${ }^{1}$, Akifumi Kishi ${ }^{2}$ and Benjamin H. Natelson ${ }^{3}$ \\ ${ }^{1}$ Educational Physiology Laboratory, Graduate School of Education, \\ The University of Tokyo, Tokyo, \\ ${ }^{2}$ Division of Pulmonary, Critical Care and Sleep Medicine, Department of Medicine, \\ NYU School of Medicine, New York, NY, \\ ${ }^{3}$ Pain and Fatigue Study Center, Beth Israel Medical Center, \\ Albert Einstein Medical Center, New York, NY, \\ ${ }^{1}$ Japan \\ 2,3USA
}

\section{Introduction}

Fibromyalgia (FM) is a medically unexplained illness characterized by four quadrant pain lasting at least 3 months and accompanied by multiple areas of tenderness on palpation of the body using $4 \mathrm{~kg}$ force. FM occurs more often in women than men but is quite common in both sexes, occurring in approximately $3 \%$ of the population. Although sleep difficulties are not part of standard diagnostic criteria, insomnia complaints of poor and nonrestorative sleep are common and have been associated with intense of pain, fatigue, sleepiness, and cognitive difficulties in FM.

FM frequently occurs in conjunction with chronic fatigue syndrome (CFS). CFS is a medically unexplained condition characterized by persistent or relapsing fatigue lasting at least 6 months, which substantially reduces normal activity. In addition to severe fatigue, one of the eight symptoms used for diagnosing CFS is "unrefreshing sleep", and this sleeprelated problem is the most common complaint among CFS patients.

Although, FM and CFS often have similar symptoms, including sleep-related complaints, differences between FM and CFS exist. In this chapter, we will review studies on sleep in FM and CFS patients in order to better understand differences between them. Polysomnographic studies have shown sleep problems in FM by using simple descriptive statistics, for instance, increased non-rapid eye movement (non-REM) Stage 1 sleep, reduced slow-wave (Stages 3 and 4) sleep, more arousals, prolonged sleep onset, reduced sleep efficiency, etc. Sleep problems in CFS shown by polysomnographic studies are quite similar to those in FM. However, we have shown that dynamic aspects of sleep, a new way of assessing sleep, are different between patients with CFS alone compared to those with CFS+FM. The probability of transition from rapid eye movement (REM) sleep to waking in CFS is greater than in healthy controls. Probabilities of transitions from waking, Stage 1 sleep, and REM sleep to Stage 2 and those from slow-wave sleep to waking and Stage 1 sleep are greater in FM+CFS than in healthy controls.

Over the course of the many decades, sleep researchers have used simple descriptive statistics to characterize and summarize sleep architecture. While this methodology has 
been extremely useful in defining the abnormalities that currently constitute sleep pathology, this approach does not explain specific patient complaints of disturbed and unrefreshing sleep. However, a dynamic analysis complements the classical approach by allowing an analysis of transition dynamics between sleep stages and shows that FM and CFS may be different illnesses associated with different problems in sleep regulation.

\section{Sleep studies and FM}

\subsection{Sleep and symptoms of FM}

Although sleep difficulties are not part of standard diagnostic criteria (Wolfe et al., 1990), insomnia complaints of poor and nonrestorative sleep are common in patients with FM. An early study shows that $65.7 \%$ of patients with FM reported nonrestorative sleep (White et al., 1999). Recently, two epidemiologic studies (Bigatti et al., 2008; Theadom et al., 2007) reported that more than $90 \%$ of patients with FM complain about sleep problems such as difficulty falling asleep, difficulty falling back to sleep after waking up during nocturnal sleep, and unrefreshing sleep. Sleep is also one of the domains which associate most strongly with the patients' overall impression of improvement (Arnold et al., 2011).

Data strongly suggest that FM-like symptoms develop following sleep disruption in healthy volunteers. Four studies in normal healthy controls (Lentz et al., 1999; Moldofsky et al., 1975; Moldofsky \& Scarisbrick, 1976; Onen et al., 2001) have reported increases in musculoskeletal pain and/or decreases in pain threshold after a period of sleep disruption or deprivation, while one study did not find this result (Older et al., 1998). Moldofsky's group found that Stage 4 sleep deprivation was associated with increasing in tenderness, musculoskeletal symptoms, and mood disturbances (Moldofsky et al., 1975; Moldofsky \& Scarisbrick, 1976). In addition, healthy volunteers with disrupted sleep produced experimentally by sound pulses every 2 minutes but with normal total sleep time had a decrease in day-time energy levels. Moreover, their ability to do complex auditory monitoring tasks was also impaired (Martin et al., 1996). These data indicate that partial sleep deprivation can produce the hallmark symptoms of FM - namely, musculoskeletal achiness, marked daytime fatigue, and cognitive problems.

One study reported that sleep disturbances led to exacerbation of pain in patients with FM (Affleck et al., 1996). One recent study reported that negative mood (i.e., depression and anxiety), which are common among chronic pain patients or poor sleepers, almost fully mediated the relationship between sleep and pain in chronic pain patients (O'Brien et al., 2010). Moderating impact of depressive symptoms on the relationship between sleep and pain was also reported in another study (O'Brien et al., 2011).

\subsection{Sleep disorders in patients with FM}

One group suggested that as many as 33\% of individuals with FM had the restless leg syndrome (Viola-Saltzman et al., 2010). Another recent study (Gold et al., 2004) reported a high rate of sleep disturbed breathing in patients with FM (i.e., 96\%). The prevalence of overweight women (Moldofsky, 2002) may contribute to sleep disturbed breathing, such as sleep apnea and inspiratory airflow limitation with arousals (Gold et al., 2004). However, one study found that patients with FM had the same frequency of sleep apnea as normal controls (Molony et al., 1986). Unpublished data from our laboratory finds rates of FM in patients with polysomnography-documented obstructive sleep apnea to be similar to those 
found in the community. A genetic study found common genetic characteristics between FM and narcolepsy (Spitzer \& Broadman, 2010).

\subsection{Sleep abnormality in patients with FM}

In contrast to studies on sleep pathology, a host of studies strongly suggest that the pattern of sleep is abnormal in many FM patients. The most consistent abnormality is significantly increased Stage 1 sleep compared to healthy controls (Anch et al., 1991; Cote \& Moldofsky, 1997; Drewes et al., 1994; Landis et al., 2004; Leventhal et al., 1995; Molony et al., 1986; Shaver et al., 1997). Sleep disturbance in patients with FM is obvious because polysomnographic studies have shown longer sleep latencies (Drewes et al., 1994; Horne \& Shackell, 1991; Landis et al., 2004), more wakefulness (Drewes et al., 1994), reduced sleep efficiency (i.e., the proportion of time spent sleeping relative to the time available for sleeping) (Drewes et al., 1994; Landis et al., 2004), reduced Stage 2 sleep (Landis et al., 2004), and reduced Stage 4 sleep (Anch et al., 1991; Lashley, 2003) in FM patients compared to healthy control subjects of similar age. Patients with FM awaken more easily (Perlis et al., 1997) and compared to healthy controls have higher levels of physical activity during the night (Affleck et al., 1996; Korszun et al., 2002).

Although sleep efficiency was comparable to that of controls, FM patients showed more arousals (Jennum et al., 1993; Molony et al., 1986) and Stage 1 sleep (Molony et al., 1986). Molony et al. reported that patients with FM had three times more microarousals (brief sleep interruptions lasting 5-19 seconds) per hour than did healthy controls (Molony et al., 1986). These results indicate that patients with FM have poor sleep quality with fragmented sleep.

An alpha-EEG anomaly during non-REM sleep has been considered a biologic correlate of chronic pain and a possible basis of nonrestorative sleep complains in patients with FM (Branco et al., 1994; Moldofsky et al., 1975; Moldofsky \& Scarisbrick, 1976; Moldofsky, 1989; Roizenblatt et al., 2001). The alpha-EEG anomaly is excessive alpha wave intrusion which has been interpreted as a heightened arousal state during non-REM sleep (Moldofsky, 1989; Scheuler et al., 1983). However, this has not been found consistently across studies (Horne \& Shackell, 1991). Alpha-delta sleep is an abnormal sleep EEG rhythm characterized by alpha activity that is superimposed on delta waves of Stages 3 and 4 sleep (McNamara, 1993). Horne and Shackell found that the mean alpha activity in Stages 2, 3, and 4 sleep were greater for the patients with FM than in healthy controls (Horne \& Shackell, 1991). Branco et al. studied alpha and delta activity and the alpha-delta ratio across sleep cycles in patients with FM and healthy controls (Branco et al., 1994). The alpha-delta sleep anomaly occurred in almost all patients who had fragmented sleep; this anomaly was not observed in any of the healthy controls. Perlis et al. found that the alpha-EEG sleep associated with perception of shallow sleep and an increased tendency to display arousal in response to external auditory stimuli (Perlis et al., 1997).

Most studies on alpha-EEG anomaly in patients with FM have been based on visual and hence relatively subjective analysis of the EEG. Using spectral analysis, a quantitative measurement is provided not only for alpha component of EEG, but also for other existing frequency components. Drewes et al. examined spectral EEG patterns and found that patients with FM showed more power in the alpha (higher frequency) band and a decrease in the lower frequency bands in Stages 2, 3, and 4 sleep and all sleep cycles (Drewes et al., 1995). However, the alpha-EEG anomaly is not specific for patients with FM in that it also occurs in healthy individuals (Horne \& Shackell, 1991; Scheuler et al., 1983; Shaver et al., 1997) and in patients with disorders such as rheumatoid arthritis and CFS (Moldofsky et al., 1983; 1988). 
A task force of the American Sleep Disorders Association has defined a cortical arousal (American Sleep Disorders Association, 1992) as a return to alpha or fast frequency EEG activity, well differentiated from the background, lasting at least 3 seconds. Cortical microarousals are briefer arousals lasting at least 1.5 seconds (Martin et al., 1997). While the major focus of sleep researchers studying arousals has been on EEG measures, one group (Pitson \& Stradling, 1998) suggested that non-EEG markers might be an important and even more reliable sign of arousals than cortical arousal as reflected by the EEG. For example, it is known that somatosensory and auditory stimulation during sleep can produce alterations in cardiac, respiratory, and somatic measures without overt EEG desynchronization (Carley et al., 1997; Halasz, 1993; Winkelman, 1999). These changes are thought to reflect activation of the brainstem or subcortical arousal system without affecting the cortex. Hence current thinking is that there are different levels of arousal responses generated from subcortical and cortical areas of the brain (Sforza et al., 2000, 2002).

One study (Sforza et al., 2000) showed that bursts of K-complexes and delta waves, expressions of an activation of subcortical arousal system, represent a real arousal response inducing cardiac activation similar to that found during cortical arousals (microarousal and phases of transitory activity). We have investigated sleep microstructure in young healthy men with no sleep complaints (Togo et al., 2006). We found increases in delta wave power in both cortical and subcortical arousals relative to just before the onset of the arousals; increases in delta power might be an even better measure of arousals than alpha wave changes.

Symptoms of unrefreshing sleep are reported to be greater when the cyclic alternating pattern (CAP, periodic appearance of delta waves and K-complexes) of EEG occupies a greater percent of sleep (Terzano \& Parrino, 2000). Sforza et al. suggested that bursts of delta waves and K-complexes were expressions of subcortical arousals representing a real arousal response with tachycardia similar to that seen during cortical arousals (Sforza et al., 2000). Patients with FM have increased amounts of CAP - more so in the more severely symptomatic patients (Rizzi et al., 2004).

\section{Sleep studies and CFS}

\subsection{Sleep disorders in patients with CFS}

One of the symptoms used for diagnosing CFS is unrefreshing sleep, and, in fact, this sleeprelated problem is the most common complaint among patients with severe medically unexplained fatigue (Unger et al., 2004). Partial sleep deprivation in healthy people can produce marked daytime fatigue (Martin et al., 1996), cognitive problems (Martin et al., 1996), and musculoskeletal achiness (Lentz et al., 1999; Moldofsky \& Scarisbrick, 1976; Onen et al., 2001), which are the hallmark symptoms of CFS.

Several early studies suggested that as many as one-half of individuals with CFS have mild sleep apnea syndrome (five or more episodes per hour of apnea/hypopnea), periodic leg movements, or the restless leg syndrome (Buchwald et al., 1994; Krupp et al., 1993). Other studies with more stringent criteria for these disorders either did not find this result (Krupp et al., 1993; Le Bon et al., 2000; Sharpley et al., 1997; Togo et al., 2008).

\subsection{Sleep abnormality in patients with CFS}

Polysomnographic studies suggest that the sleep architecture is abnormal in CFS patients. The most consistent abnormality is significantly reduced sleep efficiency when compared to controls (Fischler et al., 1997; Krupp et al., 1993; Morriss et al., 1993; Sharpley et al., 1997); 
the reported average values range from clearly abnormal (i.e., 76.5\%) (Fischler et al., 1997) to those within the normal range (i.e., 90\%) (Morriss et al., 1993). From one study providing data on individual patients' sleep efficiencies, one can estimate that $75 \%$ of CFS patients have reduced sleep efficiences (Krupp et al., 1993). Sleep disturbance in these patients is obvious because they often show increases in time needed to fall asleep (Morriss et al., 1993; Sharpley et al., 1997) and multiple periods of awakenings or arousals (Fischler et al., 1997; Morriss et al., 1993; Sharpley et al., 1997). Decrease in total duration of Stage 4 sleep has also been reported (Fischler et al., 1997).

We have recently reported the sleep architecture of a sample of female CFS patients during a fixed period of their menstrual cycle and after excluding patients with diagnosable sleep disorders and co-existing major depressive disorder to reduce patient pool heterogeneity (Togo et al., 2008). These patients differed significantly from matched controls in showing evidence of sleep disruption in the form of significantly reduced total sleep time, reduced sleep efficiency, and shorter bouts of sleep than healthy controls. In comparison with controls, sleep in CFS had little effect on either self-reported sleepiness or fatigue. And, interestingly, for patients only, ratings of sleepiness and fatigue correlated well with total sleep duration and efficiency. Dichotomizing the patients into a group that felt sleepier after a night's sleep than before sleep [a.m. sleepier] and a group that felt less sleepy after a night's sleep [a.m. less sleepy] reduced the variability of the sleep records considerably (Togo et al., 2008).

Those patients reporting less sleepiness after a night's sleep had sleep structures similar to those for healthy controls except for a shorter total sleep time and a commensurate reduction in Stage 2 sleep; moreover, they reported their fatigue and pain to diminish following sleep. In contrast, patients in the a.m. sleepier group had the greatest abnormalities of sleep architecture, including poor sleep efficiency, longer sleep latency, and more disrupted sleep as manifested by a higher percentage of short-duration sleep runs, than either controls or patients in the a.m. less sleepy group.

As the time since awakening from sleep increases, sleep latency decreases (Devoto et al., 1999), and one early study of young adults reported an average sleep latency of 30 seconds after a night of sleep deprivation (Carskadon \& Dement, 1979). We have determined latency to fall asleep for patients with CFS and healthy controls, previously habituated to sleeping in a sleep lab, after such a night of sleep deprivation in our laboratory (Nakamura et al., 2010). Nine healthy subjects fell asleep within 5 minutes, however 3 subjects took longer falling asleep within 9 minutes. The CFS patients as a group showed a significantly longer latency to fall asleep after sleep deprivation, but the study population fell out into two groups with the largest group of 10 patients falling asleep within 5 minutes. However, the remaining 5 patients remained awake for a longer period than any control, suggesting that they may have a disorder of arousal. Sleep latency following sleep deprivation correlated inversely with sleep efficiency on the normal sleep night for the patients with CFS. Our results indicate that some CFS patients may have a disorder of arousal which interferes with normal sleep and may, at least in part, be responsible for their disabling fatigue.

\subsection{Exercise and sleep in patients with CFS}

Exercise elevates core body temperature and increases total duration of slow-wave sleep in the night following exercise in healthy people (Horne \& Staff, 1983). To our knowledge, only our study (Togo et al., 2010) has compared sleep in CFS patients before and after exercise. 
Exertion is a particularly interesting thing to study in CFS because a disabling and characteristic feature of CFS patients is that even minimal exertion produces a dramatic worsening of symptoms (Komaroff \& Buchwald, 1991). No such effect occurs in healthy controls and, in fact, some reports, although anecdotal, suggest that acute exercise can actually improve sleep (Youngstedt et al., 1997).

We have used a standard cardiac-type stress test to probe effects of exertion on symptoms in CFS patients in other studies too. First we found that CFS patients reported more fatigue as much as four days after the exercise stress test (Sisto et al., 1996). Next, we used actigraphy to monitor activity before and after exercise and found that activity levels also fell significantly four days after the exercise stress test (Sisto et al., 1998). We recently replicated and extended this finding using real-time assessment techniques and demonstrated that CFS symptoms do worsen several days after maximal exercise but that neither mood nor cognitive function was affected (Yoshiuchi et al., 2007). We interpreted these changes in activity to support the patient complaint of worsening of symptoms induced by exercise or effort.

We recently investigated the influence of an acute bout of exercise on polysomnography and self-reported measures of sleep (Togo et al., 2010). CFS patients as a group have disrupted sleep characterized by significantly poorer quality sleep than controls. However, the patients as a group showed evidence of improved sleep after exercise. The results were clearer after we used the same stratification strategy that we had used in our earlier work (Togo et al., 2008), that is, splitting subjects into those who were either sleepier or less sleepy after a night's sleep. As expected, exercise improved the sleep quality of healthy controls who had reported decreased morning sleepiness after the baseline sleep night. Contrary to expectation, it had the same result in CFS patients with decreased morning sleepiness. However, patients who reported increased morning sleepiness showed no improvement in sleep disruption, but exercise did not exacerbate their sleep pathology. These patients also had the lowest average sleep efficiency of any of the groups studied. Because exercise did not produce a significant worsening of sleep morphology in CFS, the complaints of symptom worsening, which are reported to occur the next day after exertion, cannot be explained by disruption in sleep. After exercise, approximately half the patients actually sleep better than on their baseline study night, whereas the rest simply did not improve.

\section{Sleep dynamics}

\subsection{Sleep dynamics in healthy humans}

Most sleep studies have been performed based upon sleep stage scoring according to the traditional standardized criteria established by Rechtschaffen and Kales (Rechtstchaffen \& Kales, 1968). While this methodology has been extremely useful to describe sleep architecture, sleep stage analysis has been limited to simple descriptive statistics, such as total sleep time, sleep efficiency, the number of awakenings, latencies to sleep onset and REM sleep, and the total duration of each sleep stage.

Recently, sleep dynamics, such as transition probabilities among sleep stages and duration distributions of each sleep stage, has been reported by some studies in which the importance of dynamical aspects of sleep has been pointed out (Comte et al., 2006; Kishi et al., 2008, in press; Lo et al., 2002). Yassouridis et al. (Yassouridis et al., 1999) studied survival time statistics of a particular sleep stage ended by other different sleep stages with their event history analysis, a modification of the Cox regression analysis of life-tables (Cox, 1972), by assuming an exponential decay of sleep stage durations, 


$$
P(t) \sim e^{-t / \tau}
$$

where the $P(t)$ is a probability distribution of durations $t$ of a sleep stage and the $\tau$ is a constant. Lo et al. studied the dynamics of two-state asleep-awake transitions during sleep in humans, focusing on the duration distributions, and found entirely different behavior in the periods awake and asleep (Lo et al., 2002). Subsequently, they expanded their investigations in humans to other mammalian species, i.e., mice, rats, and cats (Lo et al., 2004). Durations of awake during sleep exhibited a power-law distribution for all species, while durations of sleep episode followed exponential distributions. Comte et al. investigated the transition probabilities and duration distributions of three sleep stages (awake, non-REM, and REM sleep) in rats (Comte et al., 2006). Duration statistics of REM sleep in rats took a power-law probability distribution,

$$
P(t) \sim t^{-\alpha}
$$

where the $a$ is a constant, partially devaluing the exponential survival time analysis. Finding a power-law relation in REM sleep and waking durations rather than an exponential decay characteristic of random survival times (Lo et al., 2002, 2004) points to the presence of an underlying complex mechanism governing sleep stage transitions because power-law or heavy-tailed distributions of survival times are often observed in a variety of complex systems (Sethna et al., 2001; Sornette, 2004).

We have recently investigated transition dynamics in humans for six sleep stages (awake, Stages 1, 2, 3, and 4 sleep, and REM sleep), the entire set of sleep states in humans (Kishi et al., 2008). Duration of slow-wave sleep follows a power-law probability distribution function, while the durations of Stage 1 sleep take an exponential function, those of Stage 2 sleep obey a stretched exponential form characteristic of a multifactorial decay (Sornette, 2004), and REM sleep durations follow an exponential function. We have also found a substantial number of REM to non-REM sleep transitions in humans, while this transition is reported to be virtually nonexistent in rats (Comte et al., 2006). These features likely reflect stage-specific neural activities (De Gennaro \& Ferrara, 2003; Hobson et al., 1986; Koyama \& Hayaishi, 1994; McCarley, 2007), and theories explaining different duration or survival time distributions (Sornette, 2004) might give deeper insights into the underlying mechanisms governing sleep stage regulations.

\subsection{Sleep dynamics in patients with FM and CFS}

FM and CFS share considerable overlapping symptoms, including sleep-related complaints. However, differences between FM and CFS have been reported, and research focusing on uncovering differences between these medically unexplained illnesses is helpful to understand them, rather than focusing on their similarities (Lange \& Natelson, 2009). Polysomnographic studies have shown that sleep problems in FM and CFS are quite similar, for instance, increased Stage 1 sleep, reduced slow-wave sleep, more arousals, prolonged sleep onset, reduced sleep efficiency, and the alpha-EEG anomaly, as shown in the previous sections (Fischler et al., 1997; Moldofsky, 2008; Sharpley et al., 1997; Van Hoof et al., 2007). However, these observations are not consistent between studies for both FM and CFS, and there are even cases not showing any statistical differences in normal sleep parameters between healthy controls and FM or CFS patients (Afari \& Buchwald, 2003; Chervin et al., 2009; Fischler, 1999; 
Reeves et al., 2006). In our study (Togo et al., 2008), after excluding patients with diagnosable sleep disorders, such as sleep-disturbed breathing and leg movement disorders, patients with CFS plus FM had sleep architecture similar to those of patients with CFS alone.

We have found robust differences in sleep dynamics between healthy controls and patients with CFS (Kishi et al., 2008). Although the duration distributions of each sleep stage are not different between healthy controls and patients with CFS, probabilities of transition from both Stage 1 sleep and REM sleep to awake are significantly greater in patients with CFS than healthy controls, indicating that the influence of factors interfering with the continuation of Stage 1 sleep and REM sleep may be different between healthy controls and CFS patients, while the fundamental mechanisms determining durations of each sleep stage are similar. CFS patients might not have a dysfunction in systems maintaining each sleep stage, but they may have a disturbed switching mechanism governing sleep stage transitions. Our data suggest that the major complaint of CFS patients of "unrefreshing sleep" may be derived from this sudden arousal from both Stage 1 sleep and REM sleep. One study (Burns et al., 2008) showed that sleep stage dynamics was different between patients with FM and healthy controls. Patients with FM showed a parameter that reflects shortened durations of Stage 2 sleep periods. Although shorter Stage 2 sleep durations did not predict daytime sleepiness, they did predict pain which is the main symptom in FM. Short Stage 2 sleep durations may associate with sleep fragmentation or pressure for recovery sleep.

We have recently compered dynamical aspects of sleep, such as transitions probabilities between sleep stages between CFS alone and CFS+FM patients and found differences between them, although sleep architecture did not differ between the groups (Kishi et al., in press). CFS alone has greater probabilities of transitions from REM sleep to awake than healthy controls. This result could be interpreted as a lower sleep pressure in CFS alone. In contrast, CFS+FM has greater probabilities of transitions from waking, Stage 1 sleep, and REM sleep to Stage 2 sleep and from Stage 2 sleep to slow-wave sleep than healthy controls, suggesting the increased sleep pressure in CFS+FM. Transitions from waking and REM sleep to Stage 2 sleep are unusual transitions in healthy humans (Kishi et al., 2008). CFS+FM also has greater probabilities of transitions from slow-wave sleep to waking and Stage 1 sleep, suggesting that this may be the specific sleep problem of CFS+FM.

There are reports of decreased level of central serotonin in FM patients (Juhl, 1998; Neeck \& Riedel, 1994). On the other hand, it has been observed that central serotonin responses are upregulated in CFS patients (Afari \& Buchwald, 2003; Weaver et al., 2010). We have recently reported that the administration of central monoaminergic (serotonergic and dopaminergic) antagonist alters dynamical sleep stage transitions from Stage 2 sleep to slow-wave sleep; probability of transition from Stage 2 sleep to slow-wave sleep was significantly increased when central serotonergic and dopaminergic antagonist was administered (Kishi et al., 2010). Such monoaminergic systems are closely related with pain modulation (Bannister et al., 2009). Thus, the imbalance of central monoaminergic (serotonergic) systems in FM patients would lead to abnormalities of pain modulations and sleep regulations.

\section{Conclusion}

Patients with FM and CFS often have sleep-related complaints. Polysomnographic studies have shown sleep problems in FM, i.e., increased Stage 1 sleep, reduced slow-wave sleep, 
more arousals, prolonged sleep onset, reduced sleep efficiency, the alpha-EEG anomaly during sleep. Although these problems are also shown in patients with CFS, dynamic aspects of sleep show different patterns between FM and CFS patients. Patients with CFS+FM had greater probabilities of transitions from waking, Stage 1 sleep, and REM sleep to Stage 2 sleep and from Stage 2 sleep to slow-wave sleep than healthy controls, suggesting the increased sleep pressure in CFS+FM. In contrast, CFS alone has greater probabilities of transitions from REM sleep to awake than healthy controls, suggesting the lower sleep pressure in CFS alone. Finding such differences is support for the thesis that FM is different illness from CFS, associated with different problems in sleep regulation.

\section{Acknowledgment}

This work is supported, in part, by National Institute of Health Grant AI-54478 and by Grant-in-Aid for Scientific Research (C) (22500690).

\section{References}

Afari N. \& Buchwald D. (2003). Chronic Fatigue Syndrome: a Review. The American Journal of Psychiatry, Vol.160, No.2, (February 2003), ISSN 0002-953X

Affleck G.; Urrows S.; Tennen H.; Higgins P. \& Abeles M. (1996). Sequential Daily Relations of Sleep, Pain Intensity, and Attention to Pain Among Women With Fibromyalgia. Pain, Vol.68, No.2-3, (December 1996), ISSN 0304-3959

American Sleep Disorders Association. (1992). EEG Arousals: Scoring Rules and Examples: a Preliminary Report From the Sleep Disorders Atlas Task Force of the American Sleep Disorders Association. Sleep, Vol.15, No.2, (April 1992), ISSN 0161-8105

Anch A.M.; Lue F.A.; MacLean A.W. \& Moldofsky H. (1991). Sleep Physiology and Psychological Aspects of the Fibrositis (Fibromyalgia) Syndrome. Canadian Journal of Psychology, Vol.45, No.2, (June 1991), ISSN 0008-4255

Arnold L.M.; Zlateva G.; Sadosky A.; Emir B. \& Whalen E. (2011). Correlations Between Fibromyalgia Symptom and Function Domains and Patient Global Impression of Change: a Pooled Analysis of Three Randomized, Placebo-Controlled Trials of Pregabalin. Pain Medicine, Vol.12, No.2, (February 2011), ISSN 1526-2375

Bannister K.; Bee L.A. \& Dickenson A.H. (2009). Preclinical and Early Clinical Investigations Related to Monoaminergic Pain Modulation. Neurotherapeutics : The Journal of the American Society for Experimental NeuroTherapeutics, Vol.6, No.4, (October 2009), ISSN 1933-7213

Bigatti S.M.; Hernandez A.M.; Cronan T.A. \& Rand K.L. (2008). Sleep Disturbances in Fibromyalgia Syndrome: Relationship to Pain and Depression. Arthritis and Rheumatism, Vol.59, No.7, (July 2008), ISSN 0004-3591

Branco J.; Atalaia A. \& Paiva T. (1994). Sleep Cycles and Alpha-Delta Sleep in Fibromyalgia Syndrome. The Journal of Rheumatology, Vol.21, No.6, (June 1994), ISSN 0315-162X

Buchwald D.; Pascualy R.; Bombardier C. \& Kith P. (1994). Sleep Disorders in Patients With Chronic Fatigue. Clinical Infectious Diseases, Vol.18 Suppl 1, (January 1994), ISSN $1058-4838$ 
Burns J.W.; Crofford L.J. \& Chervin R.D. (2008). Sleep Stage Dynamics in Fibromyalgia Patients and Controls. Sleep Medicine, Vol.9, No.6, (August 2008), ISSN 1389-9457

Carley D.W.; Applebaum R.; Basner R.C.; Onal E. \& Lopata M. (1997). Respiratory and Arousal Responses to Acoustic Stimulation. Chest, Vol.112, No.6, (December 1997), ISSN 0012-3692

Carskadon M.A. \& Dement W.C. (1979). Effects of Total Sleep Loss on Sleep Tendency. Perceptual and Motor Skills, Vol.48, No.2, (April 1979), ISSN 0031-5125

Chervin R.D.; Teodorescu M.; Kushwaha R.; Deline A.M.; Brucksch C.B.; Ribbens-Grimm C.; Ruzicka D.L.; Stein P.K.; Clauw D.J. \& Crofford L.J. (2009). Objective Measures of Disordered Sleep in Fibromyalgia. The Journal of Rheumatology, Vol.36, No.9, (September 2009), ISSN 0315-162X

Comte J.C.; Ravassard P. \& Salin P.A. (2006). Sleep Dynamics: a Self-Organized Critical System. Physical Review E, Statistical, Nonlinear, and Soft Matter Physics, Vol.73, No.5 Pt 2, (May 2006), ISSN 1539-3755

Cote K.A. \& Moldofsky H. (1997). Sleep, Daytime Symptoms, and Cognitive Performance in Patients With Fibromyalgia. The Journal of Rheumatology, Vol.24, No.10, (October 1997), ISSN 0315-162X

Cox D.R. (1972). Regression Models and Life-Tables. Journal of the Royal Statistical Society Series B (Methodological), Vol.34, No.2, (March 1972), ISSN 00359246

De Gennaro L. \& Ferrara M. (2003). Sleep Spindles: an Overview. Sleep Medicine Reviews, Vol.7, No.5, (October 2003), ISSN 1087-0792

Devoto A.; Lucidi F.; Violani C. \& Bertini M. (1999). Effects of Different Sleep Reductions on Daytime Sleepiness. Sleep, Vol.22, No.3, (May 1999), ISSN 0161-8105

Drewes A.M.; Nielsen K.D.; Taagholt S.J.; Bjerregard K.; Svendsen L. \& Gade J. (1995). Sleep Intensity in Fibromyalgia: Focus on the Microstructure of the Sleep Process. British Journal of Rheumatology, Vol.34, No.7, (July 1995), ISSN 0263-7103

Drewes A.M.; Svendsen L.; Nielsen K.D.; Taagholt S.J. \& Bjerregard K. (1994). Quantification of Alpha-EEG Activity During Sleep in Fibromyalgia: A Study Based on Ambulatory Sleep Monitoring. Journal of Musculoskeletal Pain, Vol.2, No.4, (1994), ISSN 1058-2452

Fischler B. (1999). Review of Clinical and Psychobiological Dimensions of the Chronic Fatigue Syndrome: Differentiation From Depression and Contribution of Sleep Dysfunctions. Sleep Medicine Reviews, Vol.3, No.2, (June 1999), ISSN 1087-0792

Fischler B.; Le Bon O.; Hoffmann G.; Cluydts R.; Kaufman L. \& De Meirleir K. (1997). Sleep Anomalies in the Chronic Fatigue Syndrome. A Comorbidity Study. Neuropsychobiology, Vol.35, No.3, (1997), ISSN 0302-282X

Gold A.R.; Dipalo F.; Gold M.S. \& Broderick J. (2004). Inspiratory Airflow Dynamics During Sleep in Women With Fibromyalgia. Sleep, Vol.27, No.3, (May 2004), ISSN 01618105

Halasz P. (1993). Arousals Without Awakening--Dynamic Aspect of Sleep. Physiology $\mathcal{E}$ Behavior, Vol.54, No.4, (October 1993), ISSN 0031-9384

Hobson J.A.; Lydic R. \& Baghdoyan H.A. (1986). Evolving Concepts of Sleep Cycle Generation: From Brain Centers to Neuronal Populations. Behavioral and Brain Sciences, Vol.9, No.3, (1986), ISSN 0140-525X 
Horne J.A. \& Shackell B.S. (1991). Alpha-Like EEG Activity in Non-REM Sleep and the Fibromyalgia (Fibrositis) Syndrome. Electroencephalography and Clinical Neurophysiology, Vol.79, No.4, (October 1991), ISSN 0013-4694

Horne J.A. \& Staff L.H. (1983). Exercise and Sleep: Body-Heating Effects. Sleep, Vol.6, No.1, (1983), ISSN 0161-8105

Jennum P.; Drewes A.M.; Andreasen A. \& Nielsen K.D. (1993). Sleep and Other Symptoms in Primary Fibromyalgia and in Healthy Controls. The Journal of Rheumatology, Vol.20, No.10, (October 1993), ISSN 0315-162X

Juhl J.H. (1998). Fibromyalgia and the Serotonin Pathway. Alternative Medicine Review : a Journal of Clinical Therapeutic, Vol.3, No.5, (October 1998), ISSN 1089-5159

Kishi A.; Natelson B.H.; Togo F.; Struzik Z.R.; Rapoport D.M.\& Yamamoto Y. (In press). Sleep-Stage Dynamics in Patients With Chronic Fatigue Syndrome With or Without Fibromyalgia. Sleep, (In press), 0161-8105

Kishi A.; Struzik Z.R.; Natelson B.H.; Togo F. \& Yamamoto Y. (2008). Dynamics of Sleep Stage Transitions in Healthy Humans and Patients With Chronic Fatigue Syndrome. American Journal of Physiology Regulatory, Integrative and Comparative Physiology, Vol.294, No.6, (June 2008), ISSN 0363-6119

Kishi A.; Yasuda H.; Matsumoto T.; Inami Y.; Horiguchi J.; Struzik Z.R. \& Yamamoto Y. (2010). Sleep Stage Transitions in Healthy Humans Altered by Central Monoaminergic Antagonist. Methods of Information in Medicine, Vol.49, No.5, (2010), ISSN 0026-1270

Komaroff A.L. \& Buchwald D. (1991). Symptoms and Signs of Chronic Fatigue Syndrome. Reviews of Infectious Diseases, Vol.13 Suppl 1, (January 1991), ISSN 0162-0886

Korszun A.; Young E.A.; Engleberg N.C.; Brucksch C.B.; Greden J.F. \& Crofford L.A. (2002). Use of Actigraphy for Monitoring Sleep and Activity Levels in Patients With Fibromyalgia and Depression. Journal of Psychosomatic Research, Vol.52, No.6, (June 2002), ISSN 0022-3999

Koyama Y. \& Hayaishi O. (1994). Firing of Neurons in the Preoptic/Anterior Hypothalamic Areas in Rat: Its Possible Involvement in Slow Wave Sleep and Paradoxical Sleep. Neuroscience Research, Vol.19, No.1, (February 1994), ISSN 0168-0102

Krupp L.B.; Jandorf L.; Coyle P.K. \& Mendelson W.B. (1993). Sleep Disturbance in Chronic Fatigue Syndrome. Journal of Psychosomatic Research, Vol.37, No.4, (May 1993), ISSN 0022-3999

Landis C.A.; Lentz M.J.; Tsuji J.; Buchwald D. \& Shaver J.L. (2004). Pain, Psychological Variables, Sleep Quality, and Natural Killer Cell Activity in Midlife Women With and Without Fibromyalgia. Brain, Behavior, and Immunity, Vol.18, No.4, (July 2004), ISSN 0889-1591

Lange, G. \& Natelson, B.H. (2009). Chronic Fatigue Syndrome, In: Functional Pain Syndromes: Presentation and Pathophysiology, 1st ed., E.A.Mayer, M.C.Bushnell, (Ed.), 245-261, IASP Press, ISBN 978-0931092756, Seattle, USA

Lashley F.R. (2003). A Review of Sleep in Selected Immune and Autoimmune Disorders. Holistic Nursing Practice, Vol.17, No.2, (March 2003), ISSN 0887-9311 
Le Bon O.; Fischler B.; Hoffmann G.; Murphy J.R.; De Meirleir K.; Cluydts R. \& Pelc I. (2000). How Significant Are Primary Sleep Disorders and Sleepiness in the Chronic Fatigue Syndrome? Sleep Research Online : SRO, Vol.3, No.2, (2000), ISSN 1096-214X

Lentz M.J.; Landis C.A.; Rothermel J. \& Shaver J.L. (1999). Effects of Selective Slow Wave Sleep Disruption on Musculoskeletal Pain and Fatigue in Middle Aged Women. The Journal of Rheumatology, Vol.26, No.7, (July 1999), ISSN 0315-162X

Leventhal L.; Freundlich B.; Lewis J.; Gillen K.; Henry J. \& Dinges D. (1995). Controlled Study of Sleep Parameters in Patients With Fibromyalgia. Journal of Clinical Rheumatology : Practical Reports on Rheumatic \& Musculoskeletal Diseases, Vol.1, No.2, (April 1995), ISSN 1076-1608

Lo C.C.; Amaral L.A.N.; Havlin S.; Ivanov P.C.; Penzel T.; Peter J.H. \& Stanley H.E. (2002). Dynamics of Sleep-Wake Transitions During Sleep. Europhysics Letters, Vol.57, No.5, (March 2002), ISSN 0295-5075

Lo C.C.; Chou T.; Penzel T.; Scammell T.E.; Strecker R.E.; Stanley H.E. \& Ivanov P.C. (2004). Common Scale-Invariant Patterns of Sleep-Wake Transitions Across Mammalian Species. Proceedings of the National Academy of Sciences of the United States of America, Vol.101, No.50, (December 2004), ISSN 0027-8424

Martin S.E.; Engleman H.M.; Deary I.J. \& Douglas N.J. (1996). The Effect of Sleep Fragmentation on Daytime Function. American Journal of Respiratory and Critical Care Medicine, Vol.153, No.4 Pt 1, (April 1996), ISSN 1073-449X

Martin S.E.; Engleman H.M.; Kingshott R.N. \& Douglas N.J. (1997). Microarousals in Patients With Sleep Apnoea/Hypopnoea Syndrome. Journal of Sleep Research, Vol.6, No.4, (December 1997), ISSN 0962-1105

McCarley R.W. (2007). Neurobiology of REM and NREM Sleep. Sleep Medicine, Vol.8, No.4, (June 2007), ISSN 1389-9457

McNamara M.E. (1993). Alpha Sleep: a Mini Review and Update. Clinical EEG (Electroencephalography), Vol.24, No.4, (October 1993), ISSN 0009-9155

Moldofsky H. (1989). Sleep and Fibrositis Syndrome. Rheumatic Diseases Clinics of North America, Vol.15, No.1, (February 1989), ISSN 0889-857X

Moldofsky H. (2002). Management of Sleep Disorders in Fibromyalgia. Rheumatic Diseases Clinics of North America, Vol.28, No.2, (May 2002), ISSN 0889-857X

Moldofsky H. (2008). The Significance of the Sleeping-Waking Brain for the Understanding of Widespread Musculoskeletal Pain and Fatigue in Fibromyalgia Syndrome and Allied Syndromes. Joint, Bone, Spine : Revue du Rhumatisme, Vol.75, No.4, (July 2008), ISSN 1297-319X

Moldofsky H.; Lue F.A. \& Smythe H.A. (1983). Alpha EEG Sleep and Morning Symptoms in Rheumatoid Arthritis. The Journal of Rheumatology, Vol.10, No.3, (June 1983), ISSN 0315-162X

Moldofsky H.; Saskin P. \& Lue F.A. (1988). Sleep and Symptoms in Fibrositis Syndrome After a Febrile Illness. The Journal of Rheumatology, Vol.15, No.11, (November 1988), ISSN 0315-162X

Moldofsky H. \& Scarisbrick P. (1976). Induction of Neurasthenic Musculoskeletal Pain Syndrome by Selective Sleep Stage Deprivation. Psychosomatic Medicine, Vol.38, No.1, (January 1976), ISSN 0033-3174 
Moldofsky H.; Scarisbrick P.; England R. \& Smythe H. (1975). Musculosketal Symptoms and Non-REM Sleep Disturbance in Patients With "Fibrositis Syndrome" and Healthy Subjects. Psychosomatic Medicine, Vol.37, No.4, (July 1975), ISSN 0033-3174

Molony R.R.; MacPeek D.M.; Schiffman P.L.; Frank M.; Neubauer J.A.; Schwartzberg M. \& Seibold J.R. (1986). Sleep, Sleep Apnea and the Fibromyalgia Syndrome. The Journal of Rheumatology, Vol.13, No.4, (August 1986), ISSN 0315-162X

Morriss R.; Sharpe M.; Sharpley A.L.; Cowen P.J.; Hawton K. \& Morris J. (1993). Abnormalities of Sleep in Patients With the Chronic Fatigue Syndrome. British Medical Journal, Vol.306, No.6886, (May 1993), ISSN 0959-8138

Nakamura T.; Togo F.; Cherniack N.S.; Rapoport D.M. \& Natelson B.H. (2010). A Subgroup of Patietns With Chronic Fatigue Syndrome May Have a Disorder of Arousal. The Open Sleep Journal No.3, (2010), ISSN 1874-6209

Neeck G. \& Riedel W. (1994). Neuromediator and Hormonal Perturbations in Fibromyalgia Syndrome: Results of Chronic Stress? Bailliere's Clinical Rheumatology, Vol.8, No.4, (November 1994), ISSN 0950-3579

O'Brien E.M.; Waxenberg L.B.; Atchison J.W.; Gremillion H.A.; Staud R.M.; McCrae C.S. \& Robinson M.E. (2011). Intraindividual Variability in Daily Sleep and Pain Ratings Among Chronic Pain Patients: Bidirectional Association and the Role of Negative Mood. The Clinical Journal of Pain, Vol.27, No.5, (June 2011), ISSN 0749-8047

O'Brien E.M.; Waxenberg L.B.; Atchison J.W.; Gremillion H.A.; Staud R.M.; McCrae C.S. \& Robinson M.E. (2010). Negative Mood Mediates the Effect of Poor Sleep on Pain Among Chronic Pain Patients. The Clinical Journal of Pain, Vol.26, No.4, (May 2010), ISSN 0749-8047

Older S.A.; Battafarano D.F.; Danning C.L.; Ward J.A.; Grady E.P.; Derman S. \& Russell I.J. (1998). The Effects of Delta Wave Sleep Interruption on Pain Thresholds and Fibromyalgia-Like Symptoms in Healthy Subjects; Correlations With Insulin-Like Growth Factor I. The Journal of Rheumatology, Vol.25, No.6, (June 1998), ISSN 0315$162 X$

Onen S.H.; Alloui A.; Gross A.; Eschallier A. \& Dubray C. (2001). The Effects of Total Sleep Deprivation, Selective Sleep Interruption and Sleep Recovery on Pain Tolerance Thresholds in Healthy Subjects. Journal of Sleep Research, Vol.10, No.1, (March 2001), ISSN 0962-1105

Perlis M.L.; Giles D.E.; Bootzin R.R.; Dikman Z.V.; Fleming G.M.; Drummond S.P. \& Rose M.W. (1997). Alpha Sleep and Information Processing, Perception of Sleep, Pain, and Arousability in Fibromyalgia. The International Journal of Neuroscience, Vol.89, No.3-4, (February 1997), ISSN 0020-7454

Pitson D.J. \& Stradling J.R. (1998). Autonomic Markers of Arousal During Sleep in Patients Undergoing Investigation for Obstructive Sleep Apnoea, Their Relationship to EEG Arousals, Respiratory Events and Subjective Sleepiness. Journal of Sleep Research, Vol.7, No.1, (March 1998), ISSN 0962-1105

Rechtstchaffen A. \& Kales A. (1968). A Manual of Standardized Terminology, Techniques and Scoring System for Sleep States of Human Subjects. US Government Printing Office, National Institute of Health Publication, Washington (DC), USA 
Reeves W.C.; Heim C.; Maloney E.M.; Youngblood L.S.; Unger E.R.; Decker M.J.; Jones J.F. \& Rye D.B. (2006). Sleep Characteristics of Persons With Chronic Fatigue Syndrome and Non-Fatigued Controls: Results From a Population-Based Study. BMC Neurology, Vol.6, (2006), ISSN 1471-2377

Rizzi M.; Sarzi-Puttini P.; Atzeni F.; Capsoni F.; Andreoli A.; Pecis M.; Colombo S.; Carrabba M. \& Sergi M. (2004). Cyclic Alternating Pattern: a New Marker of Sleep Alteration in Patients With Fibromyalgia? The Journal of Rheumatology, Vol.31, No.6, (June 2004), ISSN 0315-162X

Roizenblatt S.; Moldofsky H.; edito-Silva A.A. \& Tufik S. (2001). Alpha Sleep Characteristics in Fibromyalgia. Arthritis and Rheumatism, Vol.44, No.1, (January 2001), ISSN 00043591

Scheuler W.; Stinshoff D. \& Kubicki S. (1983). The Alpha-Sleep Pattern. Differentiation From Other Sleep Patterns and Effect of Hypnotics. Neuropsychobiology, Vol.10, No.2-3, (1983), ISSN 0302-282X

Sethna J.P.; Dahmen K.A. \& Myers C.R. (2001). Crackling Noise. Nature, Vol.410, No.6825, (March 2001), ISSN 0028-0836

Sforza E.; Jouny C. \& Ibanez V. (2000). Cardiac Activation During Arousal in Humans: Further Evidence for Hierarchy in the Arousal Response. Clinical Neurophysiology, Vol.111, No.9, (September 2000), ISSN 1388-2457

Sforza E.; Juony C. \& Ibanez V. (2002). Time-Dependent Variation in Cerebral and Autonomic Activity During Periodic Leg Movements in Sleep: Implications for Arousal Mechanisms. Clinical Neurophysiology, Vol.113, No.6, (June 2002), ISSN 1388-2457

Sharpley A.; Clements A.; Hawton K. \& Sharpe M. (1997). Do Patients With "Pure" Chronic Fatigue Syndrome (Neurasthenia) Have Abnormal Sleep? Psychosomatic Medicine, Vol.59, No.6, (November 1997), ISSN 0033-3174

Shaver J.L.; Lentz M.; Landis C.A.; Heitkemper M.M.; Buchwald D.S. \& Woods N.F. (1997). Sleep, Psychological Distress, and Stress Arousal in Women With Fibromyalgia. Research in Nursing \& Health, Vol.20, No.3, (June 1997), ISSN 0160-6891

Sisto S.A.; LaManca J.; Cordero D.L.; Bergen M.T.; Ellis S.P.; Drastal S.; Boda W.L.; Tapp W.N. \& Natelson B.H. (1996). Metabolic and Cardiovascular Effects of a Progressive Exercise Test in Patients With Chronic Fatigue Syndrome. The American Journal of Medicine, Vol.100, No.6, (June 1996), ISSN 0002-9343

Sisto S.A.; Tapp W.N.; LaManca J.J.; Ling W.; Korn L.R.; Nelson A.J. \& Natelson B.H. (1998). Physical Activity Before and After Exercise in Women With Chronic Fatigue Syndrome. QJM : Monthly Journal of the Association of Physicians, Vol.91, No.7, (July 1998), ISSN 1460-2725

Sornette D. (2004). Critical Phenomena in Natural Sciences: Chaos, Fractals, Self-Organization and Disorder: Concepts and Tools. 2nd ed. Springer, ISBN 978-3540308829, Berlin, Germany

Spitzer A.R. \& Broadman M. (2010). A Retrospective Review of the Sleep Characteristics in Patients With Chronic Fatigue Syndrome and Fibromyalgia. Pain Practice, Vol.10, No.4, (July 2010), ISSN 1530-7085 
Terzano M.G. \& Parrino L. (2000). Origin and Significance of the Cyclic Alternating Pattern (CAP). REVIEW ARTICLE. Sleep Medicine Reviews, Vol.4, No.1, (February 2000), ISSN 1087-0792

Theadom A.; Cropley M. \& Humphrey K.L. (2007). Exploring the Role of Sleep and Coping in Quality of Life in Fibromyalgia. Journal of Psychosomatic Research, Vol.62, No.2, (February 2007), ISSN 0022-3999

Togo F.; Cherniack N.S. \& Natelson B.H. (2006). Electroencephalogram Characteristics of Autonomic Arousals During Sleep in Healthy Men. Clinical Neurophysiology, Vol.117, No.12, (December 2006), ISSN 1388-2457

Togo F.; Natelson B.H.; Cherniack N.S.; FitzGibbons J.; Garcon C. \& Rapoport D.M. (2008). Sleep Structure and Sleepiness in Chronic Fatigue Syndrome With or Without Coexisting Fibromyalgia. Arthritis Research \& Therapy, Vol.10, No.3, (2008), ISSN 1478-6362

Togo F.; Natelson B.H.; Cherniack N.S.; Klapholz M.; Rapoport D.M. \& Cook D.B. (2010). Sleep Is Not Disrupted by Exercise in Patients With Chronic Fatigue Syndromes. Medicine and Science in Sports and Exercise, Vol.42, No.1, (January 2010), ISSN 01959131

Unger E.R.; Nisenbaum R.; Moldofsky H.; Cesta A.; Sammut C.; Reyes M. \& Reeves W.C. (2004). Sleep Assessment in a Population-Based Study of Chronic Fatigue Syndrome. BMC Neurology, Vol.4, (April 2004), ISSN 1471-2377

Van Hoof E.; De Becker P.; Lapp C.; Cluydts R. \& De Meirleir K. (2007). Defining the Occurrence and Influence of Alpha-Delta Sleep in Chronic Fatigue Syndrome. The American Journal of the Medical Sciences, Vol.333, No.2, (February 2007), ISSN $0002-$ 9629

Viola-Saltzman M.; Watson N.F.; Bogart A.; Goldberg J. \& Buchwald D. (2010). High Prevalence of Restless Legs Syndrome Among Patients With Fibromyalgia: a Controlled Cross-Sectional Study. Journal of Clinical Sleep Medicine, Vol.6, No.5, (October 2010), ISSN 1550-9389

Weaver S.A.; Janal M.N.; Aktan N.; Ottenweller J.E. \& Natelson B.H. (2010). Sex Differences in Plasma Prolactin Response to Tryptophan in Chronic Fatigue Syndrome Patients With and Without Comorbid Fibromyalgia. Journal of Women's Health, Vol.19, No.5, (May 2010), ISSN 1059-7115

White K.P.; Speechley M.; Harth M. \& Ostbye T. (1999). The London Fibromyalgia Epidemiology Study: Comparing the Demographic and Clinical Characteristics in 100 Random Community Cases of Fibromyalgia Versus Controls. The Journal of Rheumatology, Vol.26, No.7, (July 1999), ISSN 0315-162X

Winkelman J.W. (1999). The Evoked Heart Rate Response to Periodic Leg Movements of Sleep. Sleep, Vol.22, No.5, (August 1999), ISSN 0161-8105

Wolfe F.; Smythe H.A.; Yunus M.B.; Bennett R.M.; Bombardier C.; Goldenberg D.L.; Tugwell P.; Campbell S.M.; Abeles M.; Clark P. et al. (1990). The American College of Rheumatology 1990 Criteria for the Classification of Fibromyalgia. Report of the Multicenter Criteria Committee. Arthritis and Rheumatism, Vol.33, No.2, (February 1990), ISSN 0004-3591 
Yassouridis A.; Steiger A.; Klinger A. \& Fahrmeir L. (1999). Modelling and Exploring Human Sleep With Event History Analysis. Journal of Sleep Research, Vol.8, No.1, (March 1999), ISSN 0962-1105

Yoshiuchi K.; Cook D.B.; Ohashi K.; Kumano H.; Kuboki T.; Yamamoto Y. \& Natelson B.H. (2007). A Real-Time Assessment of the Effect of Exercise in Chronic Fatigue Syndrome. Physiology \& Behavior, Vol.92, No.5, (December 2007), ISSN 0031-9384

Youngstedt S.D.; O'Connor P.J. \& Dishman R.K. (1997). The Effects of Acute Exercise on Sleep: a Quantitative Synthesis. Sleep, Vol.20, No.3, (March 1997), ISSN 0161-8105 


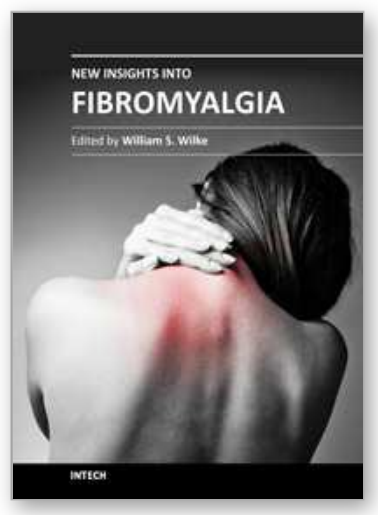

\author{
New Insights into Fibromyalgia \\ Edited by Dr. William S. Wilke
}

ISBN 978-953-307-407-8

Hard cover, 216 pages

Publisher InTech

Published online 05, January, 2012

Published in print edition January, 2012

Given the potential problems that can obscure any scientific enterprise, inconsistent results across studies are bound to occur. How are we to decide what is true? Let's turn to philosophy for a reasonable answer. The mathematician-philosopher Bertrand Russell approached a similar problem in his monograph The Problems of Philosophy (Russell B, 1912). He addressed the following question: How do we know that anything is "real"? Is the only reality subjective and simply in our minds, as Bishop Berkley challenged, or can we mostly believe the objective reality? His pragmatic answer: All possibilities may be true, but when the preponderance of evidence indicates that objective reality and knowledge are the most probable case, go with it. If the preponderance of all evidence about the clinical description of fibromyalgia and it's pathogenic mechanisms and treatment strategies indicate a highly probable interrelated hypothesis, go with it. The direction of the literature on the whole trumps the less likely tangents. At the same time, remember Bertrand Russell and his pragmatic answer, and keep an open mind.

\title{
How to reference
}

In order to correctly reference this scholarly work, feel free to copy and paste the following:

Fumiharu Togo, Akifumi Kishi and Benjamin H. Natelson (2012). Sleep and Fibromyalgia, New Insights into Fibromyalgia, Dr. William S. Wilke (Ed.), ISBN: 978-953-307-407-8, InTech, Available from: http://www.intechopen.com/books/new-insights-into-fibromyalgia/sleep-and-fibromyalgia

\section{INTECH}

open science | open minds

\author{
InTech Europe \\ University Campus STeP Ri \\ Slavka Krautzeka 83/A \\ 51000 Rijeka, Croatia \\ Phone: +385 (51) 770447 \\ Fax: +385 (51) 686166 \\ www.intechopen.com
}

\author{
InTech China \\ Unit 405, Office Block, Hotel Equatorial Shanghai \\ No.65, Yan An Road (West), Shanghai, 200040, China \\ 中国上海市延安西路65号上海国际贵都大饭店办公楼 405 单元 \\ Phone: +86-21-62489820 \\ Fax: $+86-21-62489821$
}


(C) 2012 The Author(s). Licensee IntechOpen. This is an open access article distributed under the terms of the Creative Commons Attribution 3.0 License, which permits unrestricted use, distribution, and reproduction in any medium, provided the original work is properly cited. 